\title{
Literatura e Cultura: espaços de invenção e (Re)invenção de Mundo
}

\author{
Literature and Culture: spaces of invention and (Re)invention of the World \\ Literatura y Cultura: espacios de invención y (Re)invención del Mundo
}

Ana Lúcia Montano Boéssio, Dra. ${ }^{1}$

1anaboessio@unipampa.edu.br, Universidade Federal do Pampa, Brasil

a obra literária pode ser entendida como uma tomada de consciência do mundo concreto que se caracteriza pelo sentido humano dado a esse mundo pelo autor (BORDINI e AGUIAR, 1993, p. 14).

\begin{abstract}
Resumo:
Pensando a literatura sob o estatuto de "objeto de arte" e partindo de uma abordagem comparatista, este trabalho propõe a junção de dois campos: os estudos culturais, com sua contribuição para o entendimento do conceito de cultura; e a estética, como modo de enfatizar a relevância dos estudos literários como espaço de desvelamento da cultura e do mundo. Para tanto, tem-se como referencial teórico o conceito de "cultura como invenção", proposto por Roy Wagner, e as obras de Vincent Jouve e Jean Grondin, uma vez que se entende o texto literário como espaço de confluências múltiplas e, consequentemente, não só de desvelamento mas também de invenção e/ou reinvenção da cultura à qual se relaciona, trazendo como exemplo a representação do feminino na obra o remorso de baltazar serapião, de Valter Hugo Mãe.
\end{abstract}

PALAVRAS-CHAVE: Interdisciplinaridade, Literatura, Cultura.

\begin{abstract}
:
Thinking literature as an "object of art", from a comparative approach, this paper proposes the conjunction of two fields: the Cultural Studies, with its contribution for the understanding of the concept of culture, and the Aesthetics, as a way to emphasize the relevance of literary studies as a space of unveiling of the culture and the world, as well. Therefore, this paper has as a theoretical reference the concept of "culture as invention", as proposed by Roy Wagner, and the works by Vincent Jouve and Jean Grondin, once the literary text is understood as a space of multiple confluences and, consequently, not only a space of unveiling but also of invention and/or reinvention of the culture it is related to, bringing as an example the representation of the feminine in o remorso de baltazar serapião, by Valter Hugo Mãe.
\end{abstract}

KEYWORDS: Interdisciplinarity, Literature, Culture.

\section{Resumen:}

Pensando la literatura bajo el estatuto de "objeto de arte" y partiendo de un abordaje comparatista, este trabajo propone la juntura de dos campos: los estudios culturales, con su contribución para el entendimiento del concepto de cultura; y la estética, como modo de enfatizar la relevancia de los estudios literarios como espacio de desvelo de la cultura y del mundo. Para ello, se tiene como referente teórico el concepto de "cultura como invención", propuesto por Roy Wagner, y las obras de 
Vincent Jouve y Jean Grondin, en vista de que se entiende el texto literario como espacio de confluencias múltiples y, consecuentemente, no sólo de desvelo, pero, también, de invención y/o reinvención de la cultura con la cual se relaciona, trayendo como ejemplo la representación de lo femenino en la obra o remorso de baltazar serapião, de Valter Hugo Mãe.

PALABRAS-CLAVE: Interdisciplinaridad, Literatura, Cultura.

\section{Introdução}

Segundo Armand Mattelard (2004, p. 15), os Estudos Culturais constituem o suporte de parte essencial dos debates científicos contemporâneos sobre a cultura; emergem como um paradigma, deslocando esses estudos, antes centrados no vínculo "cultura-nação", para um sentido mais amplo, antropológico. A questão central passa a ser então compreender até que ponto a cultura de um grupo funciona como contestação da ordem social ou como modo de adesão às relações de poder. Com essa nova abordagem, entram em jogo para serem reavaliados uma série de outros fatores, num processo incessante de expansão, passando a englobar outros aspectos e produções humanas e sociais: além de identidade étnica, idade e gênero, entram em cena também consumo, moda, identidades sexuais, museus, turismo, literatura, entre outros. Desse modo, os Estudos Culturais não visam apenas compreender as mudanças ocorridas na noção de cultura no final do séc. XX, eles também questionam o seu funcionamento na era da globalização e os riscos de reducionismos a ela atrelados, especialmente no que tange as dimensões econômicas, políticas e sociais que constituem essas relações. Na verdade, segundo o autor, no início do séc. XXI impõe-se pouco a pouco uma noção de cultura "instrumental, funcional com relação à necessidade de regulação social da nova ordem social" (MATTELARD, 2004, p. 195), tornando ambígua qualquer abordagem da cultura e de sua diversidade, assim como a legitimidade das políticas culturais:

As redes e indústrias da cultura e da comunicação são, em princípio, novas formas de construção da hegemonia. [...] Essa nova centralidade do cultural é homologada pela noção de soft power, toda forma de poder que não recorre à força e participa da capacidade que a potência dominante possui de fixar a ordem do dia de modo a modelar as preferências de outras nações. Inconcebível sem o crescimento em poder da arma cultural, informacional e linguística, o soft power, eufemismo que se poderia traduzir pela expressão menos vaga 'dispositivo de violência simbólica', vê-se com a tarefa de cultivar o desejo de uma ordem planetária estruturada segundo os valores do global democratic marketplace. O domínio das novas redes [...] vai permitir rentabilizar os investimentos em matéria de representação de mundo que, há 
mais de meio século, [...] a chamada 'cultura global' realizou no mundo, 'alfabetizando' os consumidores, socializando-os em um modo de vida 'global'(MATTELARD, 2004, p. 197).

Na dicotomia globalização/antiglobalização provocada pelos movimentos sociais e políticos da contemporaneidade surge, a partir de um lugar sócio-histórico, a demanda de que a cultura seja considerada um "bem público comum", tanto quanto a educação, o meio-ambiente, a saúde e a água. E, nesse contexto, os estudos culturais, ao trazer para a arena do simbólico o sociológico e o econômico, ao mesmo tempo em que atualizam suas noções de fronteiras disciplinares, tornam-se ferramenta efetiva para a análise da cultura, agora vista como prioridade.

Nesse jogo de topologias do simbólico, como é enfatizado pelos Estudos Culturais, a linguagem torna-se o lugar onde a identidade é produzida, ou seja, dentro de um discurso; e sendo a identidade relacional, a diferença é estabelecida por uma marcação simbólica relativamente a outras identidades que acontecem na fronteira com a diferença. Desse modo, as práticas e relações sociais não apenas ganham sentido, mas também definem quais os participantes incluídos e quais os excluídos do contexto social. A interação face a face torna-se então o locus no qual o indivíduo negocia as identidades, evidenciando o lugar/identidade que sustenta, sendo que, quando as diferenças interacionais permanecem despercebidas, isso pode ter sérias consequências na constituição dos sujeitos, especialmente quando se pensa a questão do gênero, uma vez que a identidade é resultado dos processos de identificação com determinadas comunidades de fala.

Portanto, partindo do conceito de "cultura como invenção", proposto por Roy Wagner, e tendo como referencial teórico as obras de Vincent Jouve e Jean Grondin, este trabalho tem por objetivo analisar o texto literário como espaço de confluências múltiplas e, consequentemente, de desvelamento, invenção e/ou reinvenção da cultura à qual se relaciona, trazendo como exemplo a representação do feminino na obra o remorso de baltazar serapião, de Valter Hugo Mãe. Ressalta-se que, por ser uma escolha do autor o uso de minúsculas inclusive para nomes próprios e início de períodos, o mesmo procedimento foi mantido aqui também.

\section{Texto Literário, Linguagem e Cultura}

Todos os livros favorecem a descoberta de sentidos, mas são os literários que o fazem de modo mais abrangente [...], a literatura dá conta da totalidade do 
real, pois, representando o particular, logra atingir uma significação mais ampla (BORDINI,1993, p. 14).

Como toda questão relevante, pensar os estudos literários permite diferentes abordagens. Uma delas é a via da linguística, já que, como afirma Vincent Jouve (2012) uma obra literária é texto, linguagem num funcionamento peculiar, ou seja, fato linguístico. Outra abordagem seria pelos estudos culturais, tendo em vista que a literatura é uma das manifestações culturais do homem em sociedade. E pode-se também pensar a literatura enquanto "arte", com todas as problematizações que o termo possa carregar e, então, cairmos num campo específico da filosofia que há muito tem se ocupado dessas questões - a estética. Este artigo propõe a junção dos dois últimos campos: os estudos culturais, com sua contribuição para o entendimento do conceito de cultura, e a estética, uma vez que aqui a literatura é apresentada com o estatuto de "objeto de arte".

Já há algum tempo, o espaço dos estudos literários tem sido de tal modo relativizado que se faz necessário relembrar que sua função transcende a mera definição e catalogação de obras e estilos; ao contrário, trata-se de oferecer ao leitor, e ao acadêmico em específico, a oportunidade de desenvolver um pensamento complexo, uma reflexão, uma prática hermenêutica. Além disso, independente do período histórico que se estude, pode-se identificar claramente um pensamento filosófico permeando, até mesmo determinando os direcionamentos no campo dos estudos literários, o que amplia significativamente a demanda de um estudo interdisciplinar. Basta que se pense nos vários sentidos que o termo hermenêutica recebeu no séc. XX; por exemplo, partindo do pressuposto de "doutrina da verdade no campo da interpretação" - a arte de interpretar corretamente um texto -, passando pela afirmação de Nietzsche de que "não há fatos, só interpretações", até chegarmos nas correntes que marcaram a segunda metade do séc. XX e que configuram o pensamento hermenêutico contemporâneo, tais como estruturalismo, pós-estruturalismo, etc. (GRONDIN, 2012). O importante é que, seja qual for o conceito e função que se atribua à hermenêutica, ela sempre será uma prática ligada à necessidade e ao desejo de interpretar, de compreender um texto, um discurso; ou seja, um instrumento de leitura de mundo numa dimensão mais ou menos geral, mais ou menos universal. Como afirmava Schleirmacher (GRONDIN, 2012, p. 28), a operação fundamental da hermenêutica ou do entendimento deveria assumir a "forma de uma reconstrução. [...], entender o discurso, de início, tão bem e, posteriormente, melhor que seu autor [...]”. 
Esse pensamento de universalização avança juntamente com a percepção de uma dimensão de estranhamento cada vez maior na pós-modernidade - o discurso do outro representando sempre um momento de estranheza. E é a partir dessas reflexões hermenêuticas que se configuram os estudos literários. Consequentemente, para que se acesse de modo efetivo qualquer teoria pós-moderna, será necessário dar um ou muitos passos atrás, em busca do pensamento filosófico que provocou ou embasou a abordagem teórico-literária contemporânea, bem como sua inserção ou relação com um determinado contexto histórico, social e cultural.

Sendo assim, para que se apreenda coma devida complexidade a representação do sujeito ficcional contemporâneo, vale relembrar aqui Stuart Hall, em A identidade cultural na pós-modernidade (2006), quando enfatiza a dificuldade que as ciências sociais encontram hoje para dar conta da complexidade do próprio conceito de identidade. $\mathrm{O}$ autor, ao discutir a "crise de identidade" da sociedade contemporânea, aponta a desestabilização do mundo social como fruto do declínio das chamadas velhas identidades, e consequentemente da passagem de um sujeito unificado para o sujeito moderno fragmentado. Na visão de Hall, as identidades modernas estão passando por um processo de descentramento, fruto das transformações nas sociedades modernas globalizadas, iniciadas no final do século XX, e que tem por marca a mudança constante, rápida e permanente. Essas mudanças, inclusive na relação do sujeito com o tempo, que se tornou muito mais acelerada, levaram à fragmentação de conceitos e práticas até então balizadoras do comportamento social e cultural do homem: questões como classe, gênero, sexualidade, etnia, raça e nacionalidade, que, no passado, representavam sólidas localizações para a identidade do sujeito social. A perda de um eixo fixo de referência torna a identidade no que o autor chama de "celebração móvel": formada e transformada continuamente em relação aos modos pelos quais somos representados ou interpelados nos sistemas culturais que nos cercam. Como afirma Anthony Giddens,

\footnotetext{
nas sociedades tradicionais, o passado é venerado e os símbolos são valorizados porque contêm e perpetuam a experiência de gerações. A tradição é um meio de lidar com o tempo e o espaço, inserindo qualquer atividade ou experiência particular na continuidade do passado, presente e futuro, os quais, por sua vez, são estruturados por práticas sociais recorrentes (GIDDENS apud HALL, 2006, pp. 37-8).
}

Já David Harvey é mais contundente ao definir modernidade, afirmando que ela não é apenas "um rompimento impiedoso com toda e qualquer condição precedente", mas 
caracteriza-se "por um processo sem-fim de rupturas e fragmentações internas no seu próprio interior" (2004, p. 12). Na visão do autor, intrinsecamente, somos constituídos por identidades contraditórias que tem na cultura nacional uma das principais fontes para uma idealizada identidade cultural unificada - a ideia de nação irá dissolver as diferenças de classe, gênero ou raça, substituindo-as pela ideia de "povo". Entretanto, a identidade é definida historicamente e não biologicamente, o que significa que o sujeito possui identidades diferentes em períodos diferentes, à medida que haja alterações nas relações e sobretudo nos turnos de poder, os quais são marcados por práticas discursivas, isto é, diferentes formas de poder cultural. A arte, e a literatura mais especificamente, consciente ou inconscientemente, direta ou indiretamente, torna-se o espaço de desvelamento desses processos sociais, culturais e até mesmo históricos, uma vez que se movimenta em sintonia com esses contextos.

Como dito anteriormente, a despeito de todos os questionamentos referentes ao objeto e à noção de arte, a reflexão estética nunca cessou: os conceitos mudaram, os espaços se ampliaram e se abriram para dimensões que transcendem o belo, o gosto, colocando a obra em contexto, numa relação direta com a cultura, a educação, a comunicação (ou impossibilidade de), com o tempo, como uma maneira particular de significar (JOUVE, 2012, p. 14). Isto porque a arte é por essência um conceito aberto.

Obviamente, não é objetivo deste artigo fazer um estudo histórico do conceito de arte, mas defender pelo prisma dos estudos culturais a relevância dos estudos literários como estratégia de leitura do homem contemporâneo, enquanto sujeito social que se constitui na exata proporção em que faz uso da linguagem. Consequentemente, enfatizase a relevância do texto literário como espaço de desvelamento da cultura e do mundo. Isto porque, assim como os Estudos Culturais, os Estudos Literários são por excelência um espaço de questionamento, igualmente marcado pelo surgimento de novos paradigmas, sobretudo no final do séc. XX. Neste caso, não mais "o que é arte", mas "o que hoje entendemos por arte" (JOUVE, 2012). A questão é, então, o que essa mudança paradigmática provoca: inevitavelmente, levará a uma ampliação do campo de estudo e sua aplicação, pois tornou-se um espaço constantemente aberto às diferentes concepções e aplicações do termo e conceito de "arte". E, apesar da afirmação de Vincent Jouve (2012, p. 29), de que as "questões que são postas à arte claramente não são postas do mesmo modo à literatura", essa mudança coloca também os estudos literários numa 
condição de "liquidez", como diria Zygmunt Bauman (2001), evidenciando a sua dimensão trans-histórica e transcultural.

Segundo Jouve (2012, pp. 35 e 36), é próprio da literatura "satisfazer ao mesmo tempo uma expectativa estética e uma exigência intelectual. [...] a forma jamais é percebida como limitada ao plano estético: o leitor também espera de sua leitura um lucro intelectual”. Esse lucro é fruto justamente das aproximações que o leitor é capaz de fazer com outros aspectos transtextuais, a partir de uma competência, em primeiro lugar, linguística. Para isso, esse leitor deverá ser necessariamente capaz de depreender a carga de ironia intertextual impregnada nos implícitos, metáforas e outros elementos linguísticos, já que linguagem e poder formam um binômio inseparável: toda relação social é marcada pelo poder, e o valor do discurso depende das relações de força entre um produtor e um consumidor desse discurso, o que significa que esse poder é permeado pela linguagem (BOURDIEU, 1977).

Portanto, levar em conta o modo como as pessoas negociam identidades sociais, ou como a situação multilíngue se configura na comunidade, real ou ficcional, adquire grande relevância por tornar-se um elemento desvelador de uma cultura que se afirma e consolida tanto pelo não dito, pela ausência de voz de alguns membros dessa comunidade, quanto pelo que se apresenta de forma explícita, considerando-se também a relatividade desses construtos linguístico-culturais, uma vez que sofrem alterações à medida que as posições de poder se alteram na arena social.

\section{A Cultura do feminino}

Talvez por ser recente - surge no final do séc. XX - a crítica feminista traz no seu cerne as marcas do sujeito da segunda, ou pós-modernidade; um sujeito desprovido de unidade, fragmentado e, por conseguinte, com sua identidade igualmente abalada, desintegrada. Sendo assim, do mesmo modo que os Estudos Culturais precisaram rever suas fronteiras interdisciplinares para dar conta de um sujeito e de uma sociedade marcados pela ambiguidade, torna-se necessário pluralizar o olhar sobre as questões do feminino, a fim de abarcar os múltiplos aspectos em jogo, já que a crítica feminista busca entender e situar o sujeito-mulher não apenas no âmbito da representação literária, mas também histórica e culturalmente através das práticas culturais de que esse sujeito se vale para se constituir, assim como das que são usadas por outros sujeitos para constituí-lo. 
Entre as várias possibilidades, E. Showalter (1994, p. 24) propõe duas modalidades de crítica centradas na figura feminina: a crítica ideológica (a mulher como leitora) e a ginocrítica (a mulher como escritora). Este segundo caso tem seu foco na caracterização da personagem, mas sobretudo na figura do narrador, uma vez que este é a instância enunciativa e, consequentemente, é a voz que posiciona os demais elementos da narrativa. Além disso, é ele o portador da ideologia constitutiva da personagem feminina e de todos os elementos que envolvem as relações da mulher na sociedade.

Tendo a diferença como ponto de partida, a autora discute também quatro modelos teóricos: de cunho biológico, para o qual o corpo define a diferença de gênero; o linguístico que vê no uso da linguagem a marcação das diferenças de gênero; o modelo psicanalítico, fundamentado em Freud e Lacan, o qual defende que as relações da mulher com a língua e as produções culturais são definidas pela ausência do falo; por último, o modelo cultural, que analisa o feminino como experiência coletiva no grupo cultural, reconhecendo a igualdade na diferença, inclusive de classe, etnia, nacionalidade, etc. Nesta perspectiva, a autora pontua a diferença como o "locus da linguagem revolucionária das mulheres", uma vez que é através da linguagem que a situação cultural da mulher, as diferenças e repressões são representadas, tornando o espaço social numa zona de confronto de valores (ROSA, 2010, p. 35). A "voz do outro" configura aqui a relação entre diálogo e ideologia, como proposto por Mikhail Bakhtin. Como afirma Graça Paulino (apud ROSA, 2010, p. 35), "se o diálogo no romance é uma forma de representar discursos dentro do discurso, dando voz às personagens, ele faz com que estas passem do nível do enunciado ao da enunciação, e, consequentemente, ele, então, interfere nas relações de poder do discurso ficcional". Então, pensar o discurso enquanto veículo de manifestação de poder torna evidente que a linguagem não apenas comunica, ela é o nosso meio de agir no mundo. E se pensarmos em termos de construção ficcional, esse processo torna-se ainda mais forte e contundente, justamente pelo tratamento que a linguagem recebe ao incorporar figuras de linguagem, além do grau de densidade e ambiguidade agregada ao significante pela carga poética:

no romance, as linguagens, com suas diversas dimensões ideológicas, sempre se entrelaçam, representando o plurilinguismo social, sem dar lugar à palavra autoritária. [...] a hibridização, a interrelação [sic] dialogizada e os diálogos puros são três categorias que se equivalem na função de criar a imagem social 
e multifacetada da linguagem no romance (BAKHTIN apud ROSA, 2010, p. 36).

Ao estabelecer uma diferença entre o lugar do autor e o do texto, Bakhtin, em Estética e Teoria do Romance (1978), afirma que, devido ao fato do discurso no romance atender a diferentes fins, pois cada enunciação do narrador e personagens constitui novos atos de fala, o discurso adquire um grau polêmico. Isto porque, a despeito do distanciamento do narrador, os valores do autor estão implícitos no texto e acabam sendo transmitidos ao leitor, o que, por um lado, pode reduzir o narrador a um mero instrumento desse processo; por outro, esse distanciamento é o que vai assegurar a polifonia do discurso, impedindo que a voz e, consequentemente, os valores do autor ganhem exclusividade na narrativa. A relação dialógica dar-se-á, na visão de Bakhtin, quando o "narrador se questiona sem anular-se, e o positivo ou negativo não se definem para o leitor" (ROSA, 2010, p. 37), chegando ao leitor na forma de ambivalência. É essa construção narrativa polifônica, ambígua, que se pode identificar na obra de Mãe, pelos atos de fala do narrador e personagem principal, baltazar.

Através de estruturas dialógicas dicotômicas entre masculino e feminino, enunciação explícita e implícita, vai se construindo um espaço polifônico, onde os atos de fala (ou ausência de) vão constituindo ao longo da narrativa um jogo crescente de forças ambivalentes e que representam as diferenças dos discursos das personagens. $\mathrm{Ou}$ seja, o diálogo, ao mesmo tempo em que representa o discurso direto entre as personagens, é também o espaço de confronto de valores e de marcação dos espaços de poder na arena social ficcional, que ganha carga de representação da própria dinâmica social no mundo.

Analisando esta questão pelo viés antropológico, Roy Wagner, em A invenção da cultura (WAGNER, 2012, p. 18), faz uma comparação entre certas ciências cujos paradigmas mantem uma imobilidade congelada, e a antropologia que, segundo o autor, é pura dialética, “um jogo de exposições (e refutações) por vozes disparatadas ou uma eclética soma de tudo e mais um pouco dentro dos manuais". Ou seja, a antropologia é uma disciplina na qual "um autor é obrigado a destilar a sua própria tradição e seu próprio consenso", elegendo observar fenômenos humanos a partir de um "exterior", entendendo, contudo, que uma perspectiva exterior é tão profundamente criada quanto as nossas mais confiáveis perspectivas “interiores”. Desse modo, a própria cultura é apresentada como 
uma espécie de ilusão, um contrapeso (e uma espécie de falso objetivo) para ajudar o antropólogo a ordenar suas experiências.

E é neste ponto que se pode estabelecer uma relação direta entre o fazer do antropólogo e o fazer do escritor literário, como é o caso do narrador da obra de Valter Hugo Mãe, baltazar, que constantemente recorre aos referenciais culturais herdados da figura paterna para orientar-se e justificar suas atitudes na relação com o outro, em especial o outro feminino, sobretudo sua mulher, ermesinda, cuja presença silente ocupa completamente o mundo psíquico de baltazar. Nessa inter-relação, fica evidente o que Wagner chama de "dinâmica cultural" (2012, p. 26), a qual é baseada na mediação de domínios de responsabilidade (e não responsabilidade) humana. baltazar configura-se como um sujeito atormentado, justamente por entender-se como responsável por honrar o contrapeso da tradição de domínio masculino sobre a educação/controle do feminino, inclusive no que se refere ao papel da mãe em relação aos filhos, que deveriam ser protegidos ao máximo da sua influência, conforme narra a personagem:

a minha mãe deixava de falar comigo e com o aldegundes, porque lhe saíam coisas de mulher boca fora, e barafustar, como fazia, era encher os ouvidos dos homens com ignorâncias perigosas uma mulher é ser de pouca fala, como se quer, parideira e calada, explicava o meu pai, ajeitada nos atributos, procriadora, cuidadosa com as crianças e calada para não estragar os filhos com os seus erros. ... liberta das intenções de nos educar coisas inúteis ou falsas, que fizessem de nós rapazes menos homens ou simplesmente iludidos com um mundo que só as mulheres imaginavam (MÃE, 2010, p. 17).

É na sua função simbólica e problematizadora, como representação do feminino, que ermesinda, apesar de desprovida de voz enquanto sujeito no "interior" daquele modelo social, constitui-se para o narrador num elemento perturbador, uma voz constante em sua mente, numa espécie de efeito contrastante, dialético. Esse contraste gera em baltazar uma crescente inquietação por ver-se induzido a reproduzir as práticas socioculturais do pai, desconstitutivas de um feminino com o qual estava "casado de igreja" e, portanto, autorizado para tê-la só sua e educá-la à maneira das suas fantasias, "como devia ser, como devia ser um pai de família, servido de esposa, a precaver tudo, a ter as vezes de responsável” (MÃE, 2010, p.22). 
À medida que o processo de desconfiguração física de ermesinda avança, começa a aflorar um princípio intuitivo, um desejo, se assim podemos chamar, de que talvez tudo pudesse ter sido diferente, o que culminará na verbalização do seu remorso nas duas últimas páginas do romance:

eu sentiria até ali o remorso dos bons homens, como havia pensado, remorso duro de tão dignamente administrar a educação da minha ermesinda. mas até ali, pensei, até ali, porque naquele momento, mais do que a condenação de restarmos os quatro encurralados para todos os avios, ocorreu-me a falha grave do meu espírito. e tão amargamente me foi claro que, por piedade ou compreensão com os meus companheiros, e talvez por ausência da voz da minha mulher, passara para lá do limite. o remorso dos bons homens já não me assistia, senão só a burrice e ignorância de quem abdicara da sua mulher (MÃE, 2010, p. 193).

Segundo Wagner (2012, p. 24), no aspecto coletivo da simbolização, os símbolos diferenciantes assimilam ou englobam as coisas que simbolizam. Este efeito, que "sempre opera para negar a distinção entre os modos", é o que o autor chama de "obviação". Focalizando a atenção nesse "controle", o simbolizador percebe o modo oposto como algo bastante diferente, uma "compulsão" ou "motivação" interna. É o que parece acontecer com baltazar, assim como com todos os outros homens de sua família que o antecederam, representados pela figura paterna, os quais demonstraram ter a mesma compulsão por controle e desconstituição do "diferente"; neste caso, o feminino, aproximado na narrativa, como dito anteriormente, a uma figura endemoniada e, portanto, perigosa, sobretudo para o futuro do sujeito masculino. Como o narrador costumava dizer, "o mundo que as mulheres imaginavam era torpe e falacioso, viam coisas e convenciamse de estupidez por opção...” (MÃE, 2010, p. 17).

Como o instrumento da literatura é a linguagem, essa invenção cultural do feminino encontra no universo narrativo de mãe um espaço especial de desvelamento, um campo fértil para provocar, perturbar um sujeito social acostumado, como baltazar, a simplesmente reproduzir automatamente a sua tradição, fazendo com que no jogo linguístico entre signo, significado e significante, este último se distancie tanto do significado que o mesmo quase se torna esquecido. Um jogo que, levado às últimas consequências, como é o caso da escrita de Valter Hugo Mãe, acaba gerando um estranhamento entre os muitos níveis de interlocução com e na obra, o que potencializa 
sua força. Porém, como afirma Lacan (1955-56), a palavra é um "signo terrível”, "quanto mais o significante nada significa, mais indestrutível ele é”.

É no trabalho sobre a linguagem que a obra de Valter Hugo Mãe excede em força e contraste, desvelando os deslocamentos nos processos de troca social e nos atos de comunicação; é na escolha dos signos linguísticos que retumba a ausência de voz, de poder na relação com o outro; que se delineia a sexualidade feminina; que a violência contra o feminino torna-se escândalo aos olhos do leitor. Na obra de Mãe, se a mulher tem voz ou movimento é assim, descontrolado, endiabrado, animalizado. As mulheres de Mãe destilam uma cultura inventada pelo homem, carregam o contrapeso de uma tradição que, se e quando questionada, nunca o é o suficiente para mudar a dinâmica de poder e voz na arena social. No universo fantástico do autor, a tradição reevocada nas interrelações entre masculino e feminino não choca, não surpreende, não espanta nem mesmo o próprio feminino, enquanto personagem. Caberá ao leitor, quietamente, digerir cada palavra, cada nome minúsculo, cada vírgula na solidão e impotência da sua condição de "outro" na obra.

\section{Considerações finais}

Feminino, literatura, cultura: pensar o feminino e suas representações, independentemente da abordagem escolhida, implica necessariamente uma análise que inclua as dimensões históricas, sociais e econômicas, mesmo quando o foco é a representação do feminino na narrativa literária. Como dito anteriormente, a linguagem não só é o material de construção da literatura, ela é também a marcação dos espaços de poder e/ou não-poder do sujeito na arena social, especialmente quando a questão é o feminino; portanto, linguagem não pode ser pensada, entendida ou estudada de modo isolado. E assim como não podemos separar literatura de linguagem, que é o seu material de construção, também não se pode separar linguagem do contexto social em que é produzida, já que é a linguagem que constitui o homem como sujeito social e consequentemente cultural.

Entendida por essa dimensão social, pode-se perceber que a linguagem do feminino passou pelo mesmo processo de apagamento por que passam todas as minorias: "a voz das mulheres sempre foi silenciada, o que a impediu de desenvolver uma linguagem própria” (ZINANI, 2013, p. 26). Isso significa que, independente da causa, o caminho para a conquista do espaço feminino dar-se-á inevitavelmente como o caminho de qualquer minoria: através da apropriação da linguagem, à medida que a mulher 
construa um discurso próprio, fruto de uma leitura de mundo cada vez mais plural e crítica. Porém, é preciso ressaltar que essa construção não deverá ocorrer apenas no âmbito sociológico ou econômico. É preciso que sua visibilidade chegue também ao campo da arte e da crítica literária propriamente femininas, transformando o silêncio milenar a que o feminino sempre esteve submetido em discurso legível, audível, fazendo o que Zinani chama de "rito de passagem", a travessia do invisível para o visível. E sendo o texto literário o espaço da imagem poética forte, capaz de provocar o realce total do psiquismo (BACHELARD, 2003), torna-se um espaço privilegiado para o desvelamento da condição social, cultural ou mesmo histórica do homem e, em especial, dessa condição de silenciamento do discurso feminino, como se pode ver em o remorso de baltazar serapião.

Num misto de realidade e ficção, num jogo perfeito entre ética e estética, entre forma e conteúdo, a obra de Mãe induz o leitor ao que Eagleton (2006, p. 6) chama de "consciência dramática da linguagem", a qual tem o poder de renovar nossas reações habituais e nos fazer perceber "objetos" que nunca ou há muito tempo não eram percebidos. Porque o texto literário tem que "lutar com a linguagem de forma mais trabalhosa, mais autoconsciente do que o usual, o mundo que essa linguagem encerra é renovado de forma intensa". E "intenso" por certo é um adjetivo que se aplica perfeitamente ao texto de Mãe, que não poupa adjetivações e neologismos para provocar um leitor que constantemente (e talvez possamos dizer, inutilmente) busca no seu próprio contrapeso cultural discursos que contradigam aquelas práticas sociais, que as mantenham distantes de uma condição real, de qualquer dimensão do contemporâneo e, principalmente, de uma condição de atualidade, de modo a se acalmar, a fazer paz com o mundo ao qual pertence. E aqui o leitor/narrador aproxima-se do antropólogo, na tentativa de construir uma ilusão; como diria Wagner, de inventar, uma visão de mundo que dê conta de qualquer "irregularidade" como acidente. Mas o mundo de baltazar aproxima-se mais do que Sperber chama de "buraco negro", uma nuvem de poeira obscurante que

equivale ao lugar onde a referência cessa; obtém "conhecimento" ao se formar uma metáfora, mas trata-se de um conhecimento forjado em um âmbito pessoal por imitação de um conhecimento “enciclopédico" (isto é, convencional) mais amplamente sustentado (SPERBER apud WAGNER, 2012, p. 28). 
O problema é que, na obra de Mãe, as metáforas, e sobretudo o jogo entre elas, são difíceis, indigestas porque saturadas de questões éticas das quais o leitor desavisado tenta escapar pelo fantástico da obra. O mundo de baltazar é um mundo não coincidente, “inatual”, como diria Agamben (2009) e, portanto, podemos dizer, verdadeiramente contemporâneo. A discronia presente em o remorso de baltazar serapião, na voz do protagonista, torna evidente a sua consciência de que não pode fugir de si mesmo; o seu tempo, ou (des)tempo pertence a ele irrevogavelmente e isso é o seu conforto e a sua sina: eles são os "sargas" e assim permanecerão naquele mundo e naquele tempo. Mas aqui o leitor não encontra mais resguardo na figura do narrador, ele é deixado a esmo, entregue a si mesmo, ciente de que Cultura, e por consequência a tradição, é matéria efêmera, intangível. Como o narrador, o leitor fica entregue a sua condição de contemporâneo e, como tal, na visão de Agamben, deverá manter o olhar fixo no seu tempo, não para perceber as suas luzes, mas o seu escuro:

... esse escuro não é uma forma de inércia ou passividade, mas implica uma atividade e uma habilidade particular que, no nosso caso, equivalem a neutralizar as luzes que provem da época para descobrir as suas trevas, o seu escuro especial, que não é, no entanto, separável daquelas luzes.

Pode dizer-se contemporâneo apenas quem não se deixa cegar pelas luzes do século e consegue entrever nessas a parte da sombra, a sua íntima obscuridade (AGAMBEN, 2009, p. 63).

Eis aí o poder do texto literário; eis aí a grande provocação da obra de Mãe: não podemos negar as sombras do nosso tempo, as trevas multisseculares que uma cultura de culpa e segregação tem gerado, e que recorrentemente tem tido sua atenção e sua força voltadas para a (des)constituição de um feminino que, como ermesinda, se faz escandalosamente audível pela insistência de uma presença silente, destituída de discurso. Apesar de não ser escrita por uma mulher, a escrita de Valter Hugo Mãe tem a marca de um texto genuinamente feminino: a polifonia; e como um texto palimpséstico, típico de uma escrita feminina, "impõe um duplo esforço de decodificação, uma vez que remete para a necessidade da leitura das entrelinhas e da interpretação do não dito, o que viabiliza o entendimento do sentido latente do texto - a história silenciada" (ZINANI, 2013, p. 27).

\section{Bibliografia}

AGAMBEN, Giorgio. O que é o contemporâneo? e outros ensaios. Chapecó: ARGOS, 2009. 
BAKHTIN, Mikhail. Estética da criação verbal. São Paulo: Martins Fontes, 1997.

Disponível em:

file://C:/Users/Aboessio/Downloads/BAKHTIN,\%20Mikhail.\%20Est\%C3\%A9tica\%2 0da\%20Cria\%C3\%A7\%C3\%A3o\%20Verbal.\%20S\%C3\%A3o\%20Paulo.\%20Martins $\% 20$ Fontes, \%202003.\%20(1).pdf

Esthetique et theorie du roman. Paris : Gallimard, 1978.

BOURDIEU, P. L'économie des échanges linguistiques. Langue Française, 34, maio 1977. Disponível em: http://ucbweb2.castelobranco.br/webcaf/arquivos/12933/11099/AEconomiadasTrocasLi ngsitcasPierreBourdieu.pdf Visitado em: 08/05/2014.

EAGLETON, Terry. Teoria da literatura. Uma introdução. São Paulo: Martins Fontes, 2006.

FREUD, Sigmund. (1932/1976). A Feminilidade. Em: Obras Completas. Vol. XXII. Rio de Janeiro: Imago.

(1923/1976). Organização genital infantil: uma interpolação na teoria da sexualidade. In: Obras Completas. Vol. XIX. Rio de Janeiro: Imago.

HALL, Stuart. A identidade cultural na pós-modernidade. Rio de Janeiro: DP\&A, 2006.

HARVEY, David. A condição pós-moderna: uma pesquisa sobre as origens da mudança cultural. São Paulo: Loyola, 2004.

LACAN, J. O Seminário livro 3, As psicoses. Rio de Janeiro, 1955-56.

MÃE, Valter Hugo. O remorso de baltazar serapião. São Paulo: Ed. 34, 2011.

MATTELARD, Armand; NEVEU, Érik. Introdução aos estudos culturais. São Paulo: Parábola, 2004.

RIBEIRO, Rosângela Maria. Relacionamento amoroso: sofrimento feminino na contemporaneidade. Dissertação de mestrado.Universidade Católica de Goiás, 2007. Disponível em: http://tede.biblioteca.ucg.br/tde_busca/arquivo.php?codArquivo=324 Site visitado em: 28/04/2014.

ROSA, Cristina (org.). Das leituras ao letramento literário. Belo Horizonte: FaE/UFMG; Pelotas: UFpel, 2010. 
SOLLER, C. (1997). O sujeito e o Outro I. Em: R. Feldstein, B. Fink, M. Jaanus (Orgs.); D. D. Estrada (Trads). Para ler o Seminário 11 de Lacan: Os quatro conceitos fundamentais da psicanálise. Rio de Janeiro: Jorge Zahar.

WAGNER, Roy. A invenção da cultura. São Paulo: Cosac Naify, 2012.

ZINANI, Cecil Jeanine A. Literatura e gênero: a construção da identidade feminina. 2 ed. Caxias do Sul: EDUCS, 2013. 